\title{
Income Taxation, Commodity Taxation and Provision of Public Goods under Labor Market Distortions
}

\author{
Thomas Aronsson and Tomas Sjögren \\ Department of Economics, University of Umea, \\ S- 90187 Umea, Sweden
}

September 2001

\begin{abstract}
This paper concerns optimal taxation and provision of a public good in the context of the mixed tax problem, where the set of tax instruments consists of a nonlinear income tax and linear commodity taxes. The analysis is based on a two-type model with endogenous wage rates. Contrary to previous studies, we allow for imperfect competition in the labor market resulting from the influence of unions over wage formation. The results imply that the employment effects associated with each policy instrument are important to consider. In addition, the effective marginal tax rate of the highest income earners may be either positive or negative. Finally, if concern for employment and/or self-selection make the government choose a lower level of unemployment income than it would otherwise have done, it will to some extent compensate the unemployed by providing more of the public good and via lower commodity taxes.
\end{abstract}

JEL Classification: D60, H21, H40, J64

Keywords: Optimal taxation, provision of public goods, unemployment 


\section{Introduction}

Since the mid 1990s, several studies on optimal taxation have been concerned with the implications of excess supply of labor. The previous studies on optimal taxation under labor market imperfections concentrate on linear tax instruments ${ }^{1}$. In this paper, we are concerned with the mixed tax problem, in which the government uses a nonlinear income tax and linear commodity taxes. The purpose is to study optimal taxation and provision of public goods in an economy with imperfect competition in the labor market.

Seminal contributions to the mixed tax problem in the context of competitive economies have been made by Atkinson and Stiglitz (1976), Mirrlees (1976) and Atkinson (1977). In their elegant summary of the literature, Edwards et al. (1994) emphasize two important aspects of optimal taxation. First, the effective marginal tax rate facing the highest income earners should be zero, or even negative in certain situations, whereas the effective marginal tax rates facing individuals with lower income should generally be nonnegative. Second, the role of commodity taxation as a supplement to nonlinear income taxation depends on whether or not leisure is weakly separable from the private consumption goods in the utility function. If it

\footnotetext{
${ }^{1}$ Andersen et al. (1996) analyze the welfare effect of a public expansion, financed by using a linear income tax, in the context of an open economy with imperfect competition in the labor market. Their results suggest that higher expenditures on a public good may be desirable even in case the public good is pure waste, if such an expansion increases employment. Bovenberg and van der Ploeg (1996) are concerned with the simultaneous choice of labor income taxation, environmental taxation and public good provision in an economy with imperfect competition in the labor market. The purpose of their paper is to study how a change in the preferences for a cleaner environment affects the optimal policy mix. Finally, Boeters and Schneider (1999), Koskela and Schöb (2000) and Aronsson and Sjögren (2001) study various aspects of the optimal mixture of linear taxes on labor and capital in an open economy, which is characterized by union wage setting.
} 
is, then a government that is able to use nonlinear income taxation has no need for commodity taxes. The latter is a result of Atkinson and Stiglitz (1976). In a more general framework, where leisure is not weakly separable from the private consumption goods, the role of commodity taxation is to weaken the self-selection constraint which restricts the choice of optimal income taxation.

The optimal provision of public goods under nonlinear income taxation has been studied by e.g. Christiansen (1981) and Boadway and Keen (1993). Christiansen shows that if the households have the same preferences, and if leisure is weakly separable from the other goods in the utility function, the optimal provision of public goods can be characterized by the Samuelson condition. This result has been generalized by Boadway and Keen (1993), showing that the sum of marginal rates of substitution between the public good and private consumption exceeds (falls short of) the marginal rate of transformation if, and only if, the marginal rate of substitution between the public good and private consumption increases (decreases) with leisure. This is a strong result and relates the deviation from the Samuelson condition to whether the public good is in a sense complementary with or substitutable for leisure. Edwards et al. (1994) study public good provision in a situation where the government uses a nonlinear income tax and linear commodity taxes to raise the revenues. Their extension essentially means adding a tax base effect to the formula derived by Boadway and Keen.

Although the previous studies have contributed considerably to our knowledge about the structure of optimal taxation and provision of public goods, they are all based on the assumption that the labor market is competitive. Since unemployment has been a severe economic problem in many countries for a long time, it is important to extend the analysis of optimal taxation and provision of public goods to economies with unemployment. Such an 
extension is particularly interesting in the context of the mixed tax problem, because it enables us to combine a set of tax instruments commonly observed in real world economies with a more realistic description of the labor market, in which the wage formation system gives rise to excess supply of labor.

In this paper, we assume that unions have an influence over wage formation. To simplify the analysis, the unions are assumed to have monopoly power in the labor market, implying that the unions determine the wage rates, while the firms then choose the number of persons to employ conditional on the wage rates. It is important to bear in mind that the monopoly union model is a special case of the more general right to manage model, in which unions and firms bargain over the wage rates. As long as the wage rates exceed the market clearing wage rates, the qualitative results with respect to optimal taxation and provision of public goods are not particularly sensitive to the choice between the monopoly union model and the right to manage model. This made us choose the monopoly union model over the more computationally burdensome right to manage model ${ }^{2}$. In addition, irrespective of the causes of imperfect competition in the labor market, an important aspect of public policy is the welfare effect associated with changes in the employment. We will, therefore, argue that most of the qualitative results with respect to how the optimal public policy needs to be adjusted are likely to carry over to situations, where the excess supply of labor is caused by some mechanism other than union wage formation.

The analysis is based on the two-type framework developed by Stern (1982) and Stiglitz (1982), in which self-selection plays a central role for policy design. Except for the description of the labor market, the model

\footnotetext{
${ }^{2} \mathrm{An}$ overview of the theories of wage formation in unionized labor markets is given by Oswald (1985).
} 
resembles that used by Edwards et al. (1994) in the sense of focusing the attention on the simultaneous choices of a nonlinear income tax, linear commodity taxes and the provision of a public good. However, since the equilibrium in our case is characterized by unemployment, the revenues are not only used for the purpose of providing a public good: the choice set of the government also includes an unemployment benefit. The model is that of a small open economy, where one of the consumption goods is produced domestically by using skilled and unskilled labor, while the other consumption goods are imported.

The outline of the paper is as follows. Section 2 concerns the optimization problems of the private agents and the unions. We will also describe the private equilibrium, which is defined conditional on the tax and expenditure policies. In section 3, we characterize the pareto efficient choices of taxation, the public good and the unemployment income, by choosing the policy instruments to maximize the utility of the employed low ability type subject to minimum utility restrictions for the employed high ability type and the unemployed, respectively. Section 4 summarizes the paper.

\section{The Model}

We will consider a small open economy with a fixed exchange rate. The economy consists of four types of decision makers: $(i)$ consumers choosing their consumption of private goods and labor supply, (ii) firms determining the number of employed persons, (iii) trade unions choosing the wage rates, and (iv) a government choosing tax rates, provision of a public good and unemployment benefits. The tax instruments facing the government are a nonlinear income tax and linear commodity taxes. 


\subsection{The Consumers}

There are two types of individuals, who differ in ability. The distinction between the two ability types is based on a productivity indicator, which is part of the production function described below. Type 1 individuals have low productivity, indicated by $a^{1}$, and type 2 individuals have high productivity, indicated by $a^{2}$, so $a^{2}>a^{1}$. This productivity difference will, in turn, influence the difference between the wage rates, $w^{1}$ and $w^{2}$. An employed individual of type $i$ earns labor income $y^{i}=w^{i} l^{i}$, where $l^{i}$ denotes the hours of work. Both types have the same quasiconcave utility function, meaning that the utility function facing type $i$ can be written as $u\left(\mathbf{c}^{i}, h^{i}, G\right)$, where $\mathbf{c}^{i}$ is a vector of private goods, $\mathbf{c}^{i}=\left(c_{1}^{i}, \ldots, c_{J}^{i}\right), G$ the public good, $h^{i}=H-l^{i}$ leisure and $H$ a time endowment. The utility function is increasing in each argument. The producer prices are denoted by $q_{j}$ for $j=1, \ldots, J$ and the small open economy framework is interpreted to mean that the producer prices are fixed. The consumer prices are given by

$$
p_{j}=q_{j}+t_{j}
$$

for $j=1, \ldots J$, where $t_{j}$ is a commodity tax.

Employed individuals of type $i$ choose $c_{1}^{i}, \ldots, c_{J}^{i}$ and $l^{i}$ to maximize the utility subject to the budget constraint. Following Christiansen (1984), it will be convenient to start by solving the utility maximization problem conditional on the hours of work. This decision problem can be written as

$$
\max _{c_{1}^{i}, \ldots, c_{J}^{i}} u\left(\mathbf{c}^{i}, H-l^{i}, G\right)
$$

subject to

$$
B^{i}=\sum_{j=1}^{J} p_{j} c_{j}^{i}
$$

in which $B^{i}$ is a fixed budget to be allocated between the $J$ commodities. By solving the conditional utility maximization problem, we obtain the con- 
ditional indirect utility function

$$
v^{i}=v\left(B^{i}, G, H-l^{i}, \mathbf{p}\right)=u\left(\mathbf{c}^{i}\left(B^{i}, G, l^{i}, \mathbf{p}\right), H-l^{i}, G\right)
$$

In equation (4), $\mathbf{p}$ is the consumer price vector, and $c_{j}^{i}=c_{j}\left(B^{i}, G, l^{i}, \mathbf{p}\right)$ is the conditional demand function for commodity $j$. The latter obeys Roy's identity

$$
c_{j}^{i}=-\frac{v_{p_{j}}^{i}}{v_{B}^{i}}
$$

where $v_{p_{j}}^{i}=\partial v^{i} / \partial p_{j}$ and $v_{B}^{i}=\partial v^{i} / \partial B^{i}$. By using equation (3), one can easily verify that the following adding-up conditions are satisfied

$$
\begin{aligned}
\sum_{j=1}^{J} q_{j} \frac{\partial c_{j}^{i}}{\partial B^{i}} & =1-\sum_{j=1}^{J} t_{j} \frac{\partial c_{j}^{i}}{\partial B^{i}} \\
\sum_{j=1}^{J} q_{j} \frac{\partial c_{j}^{i}}{\partial l^{i}} & =-\sum_{j=1}^{J} t_{j} \frac{\partial c_{j}^{i}}{\partial l^{i}}
\end{aligned}
$$

Having solved the conditional utility maximization problem, we can derive the hours of work by maximizing the conditional indirect utility function with respect to $l^{i}$ subject to the budget constraint

$$
B^{i}=w^{i} l^{i}-T\left(w^{i} l^{i}\right)+\pi
$$

where $T(\cdot)$ is the income tax function and $\pi$ the nonlabor income. The nonlabor income is tax free and consists of pure profits redistributed equally among all individuals. The first-order condition for hours of work is given by

$$
\frac{v_{h}^{i}}{v_{B}^{i}}=w^{i}\left[1-T_{y}^{i}\right]
$$

where $v_{h}^{i}=\partial v^{i} / \partial h^{i}$ and $T_{y}^{i}=T_{y}\left(y^{i}\right)$ is the marginal income tax rate.

Let us continue with the decision problem of the unemployed. Each unemployed individual receives a fixed tax-free benefit, $b$, and the budget constraint is written

$$
B^{u n}=b+\pi=\sum_{j=1}^{J} p_{j} c_{j}^{u n}
$$


By analogy to the analysis conducted above, the conditional indirect utility function is given by

$$
v^{u n}=v\left(B^{u n}, G, \mathbf{p}\right)=u\left(\mathbf{c}^{u n}\left(B^{u n}, G, \mathbf{p}\right), H, G\right)
$$

and the conditional demand functions become

$$
c_{j}^{u n}=c_{j}\left(B^{i}, G, \mathbf{p}\right)=-\frac{v_{p_{j}}^{u n}}{v_{B}^{u n}}
$$

Since individuals have identical preferences, equations (11) and (12) apply for unemployed individuals of both ability types.

\subsection{The Labor Market}

We assume that the goods market is such that the domestic firms only produce one of the $J$ commodities, whereas the other $J-1$ commodities are imported. Export revenues are used to finance imports of the $J-1$ other consumer goods.

Aggregate output, $Q$, is produced by using both types of labor

$$
Q=F\left(a^{1} L^{1}, a^{2} L^{2}\right)
$$

where $L^{1}$ and $L^{2}$ are, respectively, the total number of work-hours of unskilled and skilled individuals. The production function is increasing in each argument and strictly concave, and the two types of labor are imperfect substitutes, so $F_{12}<0$. Profit maximization means choosing $L^{i}$ such that $w^{i}=a^{i} F_{i}$ for $i=1,2$, and we can define the demands for the two types of labor as

$$
L^{i}=L^{i}\left(\stackrel{+}{a^{i}}, \overline{a^{k}},-\bar{w}^{i}, \stackrel{+}{w^{k}}, \stackrel{+}{q_{d}}\right)
$$

for $k \neq i$, where the signs indicate the direction of the partial derivatives, and $q_{d}$ is the producer price of the domestically produced commodity. For brevity, labor demand will be written $L^{i}\left(w^{i}, w^{k}\right)$. 
The economy consists of $M^{1}$ individuals of type 1 and $M^{2}$ individuals of type 2. Each ability type is organized by a union, where union $i$ chooses $w^{i}$ subject to the labor demand $L^{i}\left(w^{i}, w^{k}\right)$, while treating the labor supply of type $i$ as exogenous. The unions are also acting Nash competitors to one another in the sense that each union treats the wage rate chosen by the other union as exogenously given.

The objective of union $i$ is to choose $w^{i}$ to maximize the expected utility of the representative member

$$
\begin{aligned}
V^{i}= & \frac{L^{i}\left(w^{i}, w^{k}\right)}{l^{i} M^{i}} v\left(B^{i}, G, H-l^{i}, \mathbf{p}\right) \\
& +\left[1-\frac{L^{i}\left(w^{i}, w^{k}\right)}{l^{i} M^{i}}\right] v\left(B^{u n}, G, \mathbf{p}\right)
\end{aligned}
$$

subject to

$$
B^{i}=w^{i} l^{i}-T^{i}\left(w^{i} l^{i}\right)+\pi
$$

in which $L^{i} / l^{i}=N^{i}$ is the number of employed individuals, and $\pi$ is exogenous from the point of view of the union. The first-order condition becomes

$$
\frac{\partial V^{i}}{\partial w^{i}}=\frac{L_{w}^{i}}{l^{i} M^{i}}\left[v^{i}-v^{u n}\right]+\frac{N^{i}}{M^{i}}\left[1-T_{y}^{i}\right] l^{i} v_{B}^{i}=0
$$

The second-order condition, $\partial^{2} V^{i} / \partial\left[w^{i}\right]^{2}<0$, is assumed to be satisfied. Since the wage rate of each ability type is independent of union membership, it is also independent of the level of unemployment, where the latter is given by $U^{i}=M^{i}-N^{i}$.

Each union chooses its wage rate conditional on the wage rate chosen by the other union. This means that each union's first-order condition defines a reaction function in $w^{1}-w^{2}$ space, where the slope of each reaction function is given by

$$
\begin{aligned}
\frac{\partial w^{i}}{\partial w^{k}}= & -\frac{\left[\partial L^{i} / \partial w^{k}\right] v_{B}^{i}\left(1-T_{y}^{i}\right)}{M^{i}\left[\partial^{2} V^{i} / \partial\left[w^{i}\right]^{2}\right]} \\
& -\frac{\left[\partial^{2} L^{i} / \partial w^{i} \partial w^{k}\right]\left[v^{i}-v^{u n}\right] / l^{i}}{M^{i}\left[\partial^{2} V^{i} / \partial\left[w^{i}\right]^{2}\right]}
\end{aligned}
$$


The change in $w^{i}$ in response to an increase in $w^{k}$ can be decomposed into two effects. The first is an increase the demand for labor of type $i$, since the two types are substitutes. This effect is captured by the first term on the right hand side. The second effect is a change in the slope of the labor demand curve, which may change the wage rate chosen by union $i$ in either direction. Wage setting equilibrium occurs at the intersection of the two reaction functions.

To derive a wage equation, note that $v^{i}(\cdot)$ is a function of $B^{i}, G, l^{i}$ and $\mathbf{p}$, while $v^{u n}(\cdot)$ is a function of $B^{u n}, G$ and $\mathbf{p}$. Then, by using the fact that the labor demand for each ability type is determined by $a^{1}, a^{2}, w^{1}, w^{2}$ and $q_{d}$, we can derive reduced forms wage equations conditional on the hours of work

$$
\tilde{w}^{i}=\tilde{w}^{i}\left(B^{u n}, B^{i}, B^{k}, G, l^{i}, l^{k}, \mathbf{p}\right)
$$

for $i=1,2$, where $a^{1}, a^{2}$ and $q_{d}$ have been suppressed for notational convenience. The labor market is in equilibrium, when equations (9) and (18) are satisfied simultaneously for both ability types. In this case, the aggregate demand for labor of type $i$ is given by

$$
L^{i}=L^{i}\left(\tilde{w}^{i}\left(B^{u n}, B^{i}, B^{k}, G, l^{i}, l^{k}, \mathbf{p}\right), \tilde{w}^{k}\left(B^{u n}, B^{i}, B^{k}, G, l^{i}, l^{k}, \mathbf{p}\right)\right)
$$

Since $N^{i}=L^{i} / l^{i}$, equation (19) implies the following reduced form employment equations for $i=1,2$

$$
N^{i}=N^{i}\left(B^{u n}, B^{i}, B^{k}, G, l^{i}, l^{k}, \mathbf{p}\right)
$$

\section{Pareto Efficient Policy}

In previous studies, such as Boadway and Keen (1993) and Edwards et al. (1994), it has become common practice to write the optimization problem such that $B^{i}$ and $y^{i}$ are decision variables facing the government. For 
our purpose, however, it will be convenient to use $l^{i}$ instead of $y^{i}$ as a decision variable. The government must then choose its decision variables, $B^{1}, B^{2}, B^{u n}, l^{1}, l^{2}, G$ and $\mathbf{t}$, such that a high ability type does not wish to behave as a low ability type and vice versa. For type 2 individuals to have the same income as type 1 , they must determine their labor input such that

$$
\hat{l}^{2}=\frac{l^{1} \tilde{w}^{1}\left(B^{u n}, B^{1}, B^{2}, G, l^{1}, l^{2}, \mathbf{p}\right)}{\tilde{w}^{2}\left(B^{u n}, B^{1}, B^{2}, G, l^{1}, l^{2}, \mathbf{p}\right)}=l^{1} \phi
$$

The self-selection constraint of the high ability type is written

$$
v^{2}=v\left(B^{2}, G, H-l^{2}, \mathbf{p}\right) \geqslant \hat{v}^{2}=v\left(B^{1}, G, H-l^{1} \phi, \mathbf{p}\right)
$$

Following Edwards et al. (1994), we omit the self-selection constraint of the low ability type, since the more interesting case is where the self-selection constraint of the high ability type is binding.

There are two additional constraints facing the government; an employment restriction and the budget constraint. The employment restriction means that the number of unemployed individuals must not exceed a maximum level, $\bar{U}$. The purpose of using the employment restriction is to recognize that explicit concern for employment may influence the choice set underlying policy. This condition can be written

$$
\sum_{i=1}^{2} N^{i} \geq \sum_{i=1}^{2} M^{i}-\bar{U}
$$

The budget constraint of the government takes the form

$$
b U+r G=\sum_{i=1}^{2} N^{i} T^{i}+\sum_{i=1}^{2} N^{i} \sum_{j=1}^{J} t_{j} c_{j}^{i}+U \sum_{j=1}^{J} t_{j} c_{j}^{u n}
$$

where $r$ is the price of the public good (assumed constant throughout) and $U=\sum_{i} U^{i}$. By combining equations (1), (3), (8) and (24), the government budget constraint can be rewritten as 


$$
\begin{aligned}
r G= & q_{d} F\left(a^{1} l^{1} N^{1}, a^{2} l^{2} N^{2}\right)-\sum_{i=1}^{2} N^{i} \sum_{j=1}^{J} q_{j} c_{j}^{i} \\
& -\sum_{i=1}^{2}\left[M^{i}-N^{i}\right] \sum_{j=1}^{J} q_{j} c_{j}^{u n}
\end{aligned}
$$

The government maximizes the utility of the low ability type subject to minimum restrictions on the utilities of the high ability type and the unemployed, respectively, as well as subject to equations (22), (23) and (25). The Lagrangean becomes

$$
\begin{aligned}
\mathfrak{L}= & v^{1}+\mu\left[v^{2}-\bar{u}^{2}\right]+\beta\left[v^{u n}-\bar{u}^{u n}\right]-\theta\left[\sum_{i=1}^{2}\left[M^{i}-N^{i}\right]-\bar{U}\right] \\
& +\lambda\left[v^{2}-\hat{v}^{2}\right]+\gamma\left[q_{d} F\left(a^{1} l^{1} N^{1}, a^{2} l^{2} N^{2}\right)-\sum_{i=1}^{2} N^{i} \sum_{j=1}^{J} q_{j} c_{j}^{i}\right. \\
& \left.-\sum_{i=1}^{2}\left[M^{i}-N^{i}\right] \sum_{j=1}^{J} q_{j} c_{j}^{u n}-r G\right]
\end{aligned}
$$

where $N^{i}$ satisfies equation (20).

\subsection{Effective Marginal Tax Rates}

By using equations (1), (8) and (10), the first order conditions for $l^{1}, B^{1}, l^{2}$ and $B^{2}$ can be written as

$$
\begin{aligned}
v_{h}^{1} & =\lambda \hat{v}_{h}^{2}\left[\phi+\frac{\partial \phi}{\partial l^{1}} l^{1}\right]+\gamma\left[\tilde{w}^{1} N^{1}-N^{1} \sum_{j=1}^{J} q_{j} \frac{\partial c_{j}^{1}}{\partial l^{1}}+\eta_{l}^{1}\right] \\
v_{B}^{1} & =\lambda \hat{v}_{B}^{2}-\lambda \hat{v}_{h}^{2} \frac{\partial \phi}{\partial B^{1}} l^{1}+\gamma N^{1} \sum_{j=1}^{J} q_{j} \frac{\partial c_{j}^{1}}{\partial B^{1}}-\gamma \eta_{B}^{1} \\
{[\mu+\lambda] v_{h}^{2} } & =\lambda \hat{v}_{h}^{2} \frac{\partial \phi}{\partial l^{2}} l^{1}+\gamma\left[\tilde{w}^{2} N^{2}-N^{2} \sum_{j=1}^{J} q_{j} \frac{\partial c_{j}^{2}}{\partial l^{2}}+\eta_{l}^{2}\right] \\
{[\mu+\lambda] v_{B}^{2} } & =-\lambda \hat{v}_{h}^{2} \frac{\partial \phi}{\partial B^{2}} l^{1}+\gamma N^{2} \sum_{j=1}^{J} q_{j} \frac{\partial c_{j}^{2}}{\partial B^{2}}-\gamma \eta_{B}^{2}
\end{aligned}
$$


where $\hat{v}_{B}^{2}=\partial \hat{v}^{2} / \partial B^{1}, \hat{v}_{h}^{2}=\partial \hat{v}^{2} / \partial h^{2}$ and

$$
\begin{aligned}
\eta_{l}^{1} & =\frac{\theta}{\gamma} \sum_{i=1}^{2} \frac{\partial N^{i}}{\partial l^{1}}+\sum_{i=1}^{2}\left[\left[b+T^{i}\right]+\sum_{j=1}^{J} t_{j}\left[c_{j}^{i}-c_{j}^{u n}\right]\right] \frac{\partial N^{i}}{\partial l^{1}} \\
\eta_{B}^{1} & =\frac{\theta}{\gamma} \sum_{i=1}^{2} \frac{\partial N^{i}}{\partial B^{1}}+\sum_{i=1}^{2}\left[\left[b+T^{i}\right]+\sum_{j=1}^{J} t_{j}\left[c_{j}^{i}-c_{j}^{u n}\right]\right] \frac{\partial N^{i}}{\partial B^{1}} \\
\eta_{l}^{2} & =\frac{\theta}{\gamma} \sum_{i=1}^{2} \frac{\partial N^{i}}{\partial l^{2}}+\sum_{i=1}^{2}\left[\left[b+T^{i}\right]+\sum_{j=1}^{J} t_{j}\left[c_{j}^{i}-c_{j}^{u n}\right]\right] \frac{\partial N^{i}}{\partial l^{2}} \\
\eta_{B}^{2} & =\frac{\theta}{\gamma} \sum_{i=1}^{2} \frac{\partial N^{i}}{\partial B^{2}}+\sum_{i=1}^{2}\left[\left[b+T^{i}\right]+\sum_{j=1}^{J} t_{j}\left[c_{j}^{i}-c_{j}^{u n}\right]\right] \frac{\partial N^{i}}{\partial B^{2}}
\end{aligned}
$$

The total tax paid by an individual of type $i$ is given by

$$
\tau\left(y^{i}\right)=T\left(y^{i}\right)+\sum_{j=1}^{J} t_{j} c_{j}\left(y^{i}-T\left(y^{i}\right)+\pi, g, \frac{y^{i}}{w^{i}}, \mathbf{p}\right)
$$

Differentiating equation (31) with respect to $y^{i}$ gives the marginal effective tax rate

$$
\tau_{y}^{i}=T_{y}^{i}+\sum_{j=1}^{J} t_{j}\left[\left[1-T_{y}^{i}\right] \frac{\partial c_{j}^{i}}{\partial B^{i}}+\frac{1}{w^{i}} \frac{\partial c_{j}^{i}}{\partial l^{i}}\right]
$$

We are now in the position to characterize the effective marginal tax rates facing employed individuals of both ability types. Consider first the effective marginal tax rate facing the low ability type;

Proposition 1 If the equilibrium is characterized by unemployment, Pareto efficient taxation under union wage setting means that the effective marginal tax rate facing the employed low ability type is characterized by ${ }^{3}$

$$
\tau_{y}^{1}=\frac{\lambda^{*}}{N^{1}}\left[\frac{\hat{v}_{y}^{2}}{\hat{v}_{B}^{2}}\left(1+\varepsilon_{l}^{1}\right)-\frac{v_{y}^{1}}{v_{B}^{1}}\left(1+\chi^{1}\right)\right]-\frac{\eta_{l}^{1}+\left(v_{h}^{1} / v_{B}^{1}\right) \eta_{B}^{1}}{\widetilde{w}^{1} N^{1}}
$$

\footnotetext{
${ }^{3}$ By defining $l^{i}=y^{i} / w^{i}$, it follows that

$$
v_{y}^{i}=-\frac{1}{w^{i}} v_{h}^{i}
$$
}


where $\lambda^{*}=\lambda \hat{v}_{B}^{2} / \gamma$ and

$$
\chi^{1}=\frac{\hat{v}_{y}^{2}}{\hat{v}_{B}^{2}} \frac{\widetilde{w}^{1} l^{1}}{B^{1}} \varepsilon_{B}^{1}, \quad \varepsilon_{l}^{1}=\frac{\partial \phi}{\partial l^{1}} \frac{l^{1}}{\phi}, \quad \varepsilon_{B}^{1}=\frac{\partial \phi}{\partial B^{1}} \frac{B^{1}}{\phi}
$$

Proof. See the Appendix.

Consider first the special case with fixed wage rates and zero unemployment, which means that $\varepsilon_{l}^{1}=\varepsilon_{B}^{1}=\eta_{l}^{1}=\eta_{B}^{1}=0$. The right hand side of equation (33) then reduces to read

$$
\tau_{y}^{1}=\frac{\lambda^{*}}{N^{1}}\left[\frac{\hat{v}_{y}^{2}}{\hat{v}_{B}^{2}}-\frac{v_{y}^{1}}{v_{B}^{1}}\right]
$$

By assuming that the high ability type has flatter indifference curves in $y-B$ space than the low ability type, equation (34) implies that individuals of the low ability type face a strictly positive effective marginal tax rate. This result is well known from previous research.

Returning to the more general case, note that taxation influences the wage ratio. If the wage ratio is nonincreasing in $l^{1}$, meaning that $\varepsilon_{l}^{1} \leq 0$, it is clear that $\varepsilon_{l}^{1}$ contributes to increase the effective marginal tax rate. If, on the other hand, the wage ratio is strictly increasing in $l^{1}$, in which case $\varepsilon_{l}^{1}>0$, there is an incentive to reduce the effective marginal tax rate and we can no longer rule out the possibility that the effective marginal tax rate is negative. The reason is that if the wage ratio increases, type 2 must put in extra effort (increase $\hat{l}^{2}$ ) to mimic type 1 . This makes mimicking less attractive, which increases the choice set of the government and provides an incentive to induce type 1 to supply more work hours via the lower effective marginal tax rate.

In a similar way, the term $\chi^{1}$ captures the influence of $B^{1}$ on the wage ratio. If $\partial \phi / \partial B^{1}>0$, there is an incentive to reduce the effective marginal tax rate, whereas $\partial \phi / \partial B^{1}<0$ provides the opposite incentive for the government. Therefore, with $\partial \phi / \partial B^{1}>0(<0)$, mimicking becomes less (more) attractive, which induces the government to set a higher (lower) $B^{1}$. 
Since the equilibrium is characterized by unemployment, tax policy will also influence the welfare via changes in employment. The latter is captured by the last term in equation (33). Changes in the employment are important for two reasons. First, if the employment restriction is binding $(\theta>0)$, government actions are restricted in case they reduce the employment. Second, changes in the employment affect the tax revenues. Each individual that becomes employed gives rise to a net revenue improvement equal to

$$
\left[b+T^{i}\right]+\sum_{j=1}^{J} t_{j}\left[c_{j}^{i}-c_{j}^{u n}\right]
$$

Since employed individuals have higher income that the unemployed, one would normally expect that the total payment of commodity taxes by an employed individual exceeds the payment made by an unemployed. This means that equation (35) can be expected to be positive. Therefore, if the net effect on employment following from higher marginal taxation is positive (negative), there is an additional incentive to choose a higher (lower) effective marginal tax rate than in the absence of unemployment.

Turning to the effective marginal tax rate facing employed individuals of the high ability type, we find;

Proposition 2 If the equilibrium is characterized by unemployment, Pareto efficient taxation under union wage setting means that the effective marginal tax rate facing the employed high ability type is characterized by

$$
\tau_{y}^{2}=\frac{\lambda^{*}}{N^{2}} \frac{\widetilde{w}^{1} l^{1}}{\widetilde{w}^{2} l^{2}}\left[\frac{\hat{v}_{y}^{2}}{\hat{v}_{B}^{2}} \varepsilon_{l}^{2}-\frac{v_{y}^{2}}{v_{B}^{2}} \chi^{2}\right]-\frac{\eta_{l}^{2}+\left(v_{h}^{2} / v_{B}^{2}\right) \eta_{B}^{2}}{\tilde{w}^{2} N^{2}}
$$

where

$$
\chi^{2}=\frac{\hat{v}_{y}^{2}}{\hat{v}_{B}^{2}} \frac{\widetilde{w}^{2} l^{2}}{B^{2}} \varepsilon_{B}^{2}, \quad \varepsilon_{l}^{2}=\frac{\partial \phi}{\partial l^{2}} \frac{l^{2}}{\phi}, \quad \varepsilon_{B}^{2}=\frac{\partial \phi}{\partial B^{2}} \frac{B^{2}}{\phi}
$$

The proof of Proposition 2 is analogous to the proof of Proposition 1 and is, therefore, omitted. In the special case with exogenous wage rates and zero 
unemployment, we have $\varepsilon_{l}^{2}=\varepsilon_{B}^{2}=\eta_{l}^{2}=\eta_{B}^{2}=0$ and $\tau_{y}^{2}=0$. This situation means that the effective marginal tax rate is zero, which has been discussed by Edwards et al. (1994).

To interpret Proposition 2, note that the self-selection constraint influences the effective marginal tax rate via the wage ratio. If $\varepsilon_{l}^{2}>0$, this means that the high ability type must supply more hours of work to mimic the low ability type, which makes mimicking less attractive. This provides an incentive to stimulate the labor supply of the high ability type by reducing the effective marginal tax rate. A similar result has been derived by Stiglitz (1982) in the context of a competitive labor market. On the other hand, if $\varepsilon_{l}^{2}<0$, the high ability type needs to put in less effort to mimic the low ability type, which induces the government to restrict $l^{2}$ by choosing a higher effective marginal tax rate. The latter suggests that the effective marginal tax rate may become positive. By analogy to the interpretation of $\varepsilon_{l}^{2}$, the term $\chi^{2}$ reflects the influence of $B^{2}$ on the wage ratio. If $\partial \phi / \partial B^{2}>0$ $(<0)$, so $\chi^{2}<0(>0)$, there is an incentive to reduce (increase) the effective marginal tax. Note finally that $\left[\eta_{l}^{2}+\left(v_{h}^{2} / v_{B}^{2}\right) \eta_{B}^{2}\right] /\left(\tilde{w}^{2} N^{2}\right)$ has the same interpretation as the corresponding expression in equation (33).

\subsection{Efficient Unemployment Income}

By using equations (1), (8) and (10), the first order condition for the unemployment income can be written as

$$
\beta v_{B}^{u n}+\lambda \hat{v}_{h}^{2} l^{1} \frac{\partial \phi}{\partial B^{u n}}-\gamma U \sum_{j=1}^{J} q_{j} \frac{\partial c_{j}^{u n}}{\partial B^{u n}}+\gamma \eta^{3}=0
$$

where

$$
\eta^{3}=\frac{\theta}{\gamma} \sum_{i=1}^{2} \frac{\partial N^{i}}{\partial B^{u n}}+\sum_{i=1}^{2}\left[\left[b+T^{i}\right]+\sum_{j=1}^{J} t_{j}\left[c_{j}^{i}-c_{j}^{u n}\right]\right] \frac{\partial N^{i}}{\partial B^{u n}}
$$


Therefore, conditional on the tax structure and the provision of the public good, the optimal unemployment benefit can be characterized as follows;

Proposition 3 A Pareto efficient level of unemployment income requires that

$$
v_{B}^{u n}=-\frac{\lambda \hat{v}_{h}^{2}}{\beta} l^{1} \frac{\partial \phi}{\partial B^{u n}}+\frac{\gamma}{\beta} U\left[1-\sum_{j=1}^{J} t_{j} \frac{\partial c_{j}^{u n}}{\partial B^{u n}}\right]-\frac{\gamma}{\beta} \eta^{3}
$$

The first term on the right hand side of equation (38) reflects the influence of the self-selection constraint, which is part of the policy rule because $B^{u n}$ affects the wage ratio. If $\partial \phi / \partial B^{u n}>0(<0)$, higher unemployment income makes mimicking less (more) attractive and provides an incentive for the government to choose a higher (lower) unemployment income than when the wage rates are fixed. The second term on the right hand side measures two of the budget effects associated with an increase in the unemployment income: the first is the direct effect, and the second measures how the unemployment income influences the tax revenues from commodity taxation via changes in the pattern of commodity demands.

The third term, $\gamma \eta^{3} / \beta$, is the employment effect associated with the unemployment income. In a way similar to the analysis conducted above, the employment effect depends on the employment restriction and the government budget constraint. If the unions choose to increase the wage rates in response to an increase in the unemployment income ${ }^{4}$, and if the cross wage effect in each labor demand function is not "too strong", one would normally expect that $\partial N^{i} / \partial B^{u n}<0$ for $i=1,2$. The employment restriction and the government's budget constraint will then contribute to reduce the unemployment income.

\footnotetext{
${ }^{4}$ Note that each union increases its wage rate as a response to an increase in the unemployment income conditional on the wage rate chosen by the other union, which can be seen by differentiating equation (16) with respect to $w^{i}$ and $b$. This suggests that the final outcome will depend on the slope of the reaction functions.
} 


\subsection{Commodity Taxation}

By differentiating the Lagrangean with respect to $p_{j}$ and using Roy's identity, we obtain the following first-order conditions for the $J$ commodity taxes

$$
\begin{aligned}
0= & -v_{B}^{1} c_{j}^{1}-[\mu+\lambda] v_{B}^{2} c_{j}^{2}-\beta v_{B}^{u n} c_{j}^{u n}+\lambda \hat{v}_{B}^{2} \hat{c}_{j}^{2}+\lambda \hat{v}_{h}^{2} l^{1} \frac{\partial \phi}{\partial p_{j}} \\
& -\gamma\left[\sum_{i=1}^{2} N^{i} \sum_{k=1}^{J} q_{k} \frac{\partial c_{k}^{i}}{\partial p_{j}}+U \sum_{k=1}^{J} q_{k} \frac{\partial c_{k}^{u n}}{\partial p_{j}}\right]+\gamma \eta_{j}^{4}
\end{aligned}
$$

where

$$
\eta_{j}^{4}=\frac{\theta}{\gamma} \sum_{i=1}^{2} \frac{\partial N^{i}}{\partial p_{j}}+\sum_{i=1}^{2}\left[\left[b+T^{i}\right]+\sum_{k=1}^{J} t_{k}\left[c_{k}^{i}-c_{k}^{u n}\right]\right] \frac{\partial N^{i}}{\partial p_{j}}
$$

To derive equation (39), we have used equations (1), (8) and (10). We can then derive the following result;

Proposition 4 If the equilibrium is characterized by unemployment, Pareto efficient taxation under union wage setting requires that

$$
\Gamma_{j}=\lambda^{*}\left[c_{j}^{1}-\hat{c}_{j}^{2}\right]-\frac{\lambda \hat{v}_{h}^{2} l^{1}}{\gamma} \frac{\partial \phi}{\partial p_{j}}-\eta_{j}^{4}-\Omega_{j}, \quad j=1, \ldots, J
$$

where

$$
\begin{aligned}
\Gamma_{j} & =\sum_{i=1}^{2} N^{i} \sum_{k=1}^{J} t_{k} \frac{\partial \bar{c}_{j}^{i}}{\partial p_{k}}+U \sum_{k=1}^{J} t_{k} \frac{\partial \bar{c}_{j}^{u n}}{\partial p_{k}} \\
\Omega_{j} & =\sum_{i=1}^{2} \psi^{i} c_{j}^{i}+\psi^{u n} c_{j}^{u n}
\end{aligned}
$$

in which $\bar{c}_{j}^{i}$ and $\bar{c}_{j}^{u n}$ are compensated commodity demand functions and

$\psi^{1}=\frac{\lambda \hat{v}_{h}^{2}}{\gamma} l^{1} \frac{\partial \phi}{\partial B^{1}}+\eta_{B}^{1}, \quad \psi^{2}=\frac{\lambda \hat{v}_{h}^{2}}{\gamma} l^{1} \frac{\partial \phi}{\partial B^{2}}+\eta_{B}^{2}, \quad \psi^{u n}=\frac{\lambda \hat{v}_{h}^{2}}{\gamma} l^{1} \frac{\partial \phi}{\partial B^{u n}}+\eta^{3}$

Proof. See the Appendix.

Once again, consider first the special case with fixed wage rates and zero unemployment. Equation (40) then reduces to

$$
\sum_{i=1}^{2} N^{i} \sum_{k=1}^{J} t_{k} \frac{\partial \bar{c}_{j}^{i}}{\partial p_{k}}=\lambda^{*}\left[c_{j}^{1}-\hat{c}_{j}^{2}\right], \quad j=1, \ldots, J
$$


Equation (41) has a simple interpretation. For a given $\lambda^{*}$, the proportionate reduction in the compensated demand for commodity $j$ is greater, the greater the difference between the consumption of commodity $j$ by the mimicker and the consumption of commodity $j$ by the low ability type. The intuition is that, when the income tax is optimally chosen, the purpose of commodity taxes is to discourage mimicking. It is also clear from equation (41) that if the utility function is weakly separable in leisure, in which case $c_{j}^{1}=\widehat{c}_{j}^{2}$ for $j=1, \ldots, J$, a government that is able to use nonlinear income taxes has no need for linear commodity taxes.

By multiplying equation (40) by $t_{j}$ and summing over $j$, we find

$$
\begin{aligned}
\sum_{j=1}^{J} t_{j} \Gamma_{j}= & \lambda^{*}\left[\sum_{j=1}^{J} t_{j} c_{j}^{1}-\sum_{j=1}^{J} t_{j} \hat{c}_{j}^{2}\right] \\
& -\sum_{j=1}^{J} t_{j} \frac{\lambda \hat{v}_{h}^{2} l^{1}}{\gamma} \frac{\partial \phi}{\partial p_{j}}-\sum_{j=1}^{J} t_{j} \eta_{j}^{4}-\sum_{j=1}^{J} t_{j} \Omega_{j}
\end{aligned}
$$

If the Slutsky substitution matrix is of full rank and, therefore, negative definite, the left-hand side of equation (42) is negative. With fixed wage rates and zero unemployment, the last three terms drop out, and equation (42) will imply that the mimicker pays more commodity taxes than the low ability type. This situation is analyzed by Edwards el al. (1994).

By comparing equations (40) and (41), we can see that endogenous wage rates and unemployment, together, imply three additional terms on the right hand side of the tax formula. First, the government must recognize how commodity taxation affects the wage ratio. If $\partial \phi / \partial p_{j}>0(<0)$, higher taxation of commodity $j$ makes mimicking less (more) attractive. It is particularly interesting to recognize the situation where mimicking becomes less attractive, since it means that concern for self-selection does no longer necessitate that the mimicker pays more commodity taxes than the low ability type, provided that the wage ratio increases sufficiently. Second, if higher commodity taxation increases (decreases) employment, i.e. $\eta_{j}^{4}>0(<0)$, there 
is an additional gain (cost) associated with commodity taxation. The interpretation of this employment effect is analogous to the interpretations of the employment effects associated with the other policy instruments. The final term on the right hand side of equation (40) is related to the optimal combinations of $B^{u n}, B^{1}, B^{2}$ and $G$. We will, therefore, leave the interpretation of this term to the next subsection.

\subsection{Efficient Provision of the Public Good}

To characterize the provision of the public good, denote $M R S_{G B}^{i}=v_{G}^{i} / v_{B}^{i}$, $M R S_{G B}^{u n}=v_{G}^{u n} / v_{B}^{u n}$ and

$$
\hat{M R S}_{G B}^{2}=\frac{\partial \hat{v}^{2} / \partial G}{\partial \hat{v}^{2} / \partial B^{1}}
$$

The results are summarized as follows;

Proposition 5 Pareto efficient provision of the public good requires that the sum of the marginal rates of substitution between the public good and private income satisfies

$$
\begin{aligned}
& \sum_{i=1}^{2} N^{i} \times M R S_{G B}^{i}+U \times M R S_{G B}^{u n} \\
&= r+\lambda^{*}\left[M \hat{R}_{G B}^{2}-M R S_{G B}^{1}\right] \\
&-\left[\sum_{i=1}^{2} N^{i} \sum_{j=1}^{J} t_{j} \frac{\partial \bar{c}_{j}^{i}}{\partial G}+U \sum_{j=1}^{J} t_{j} \frac{\partial \bar{c}_{j}^{u n}}{\partial G}\right] \\
&- \frac{\lambda}{\gamma} \hat{v}_{h}^{2} l^{1} \frac{\partial \phi}{\partial G}-\eta^{5}+\Phi
\end{aligned}
$$

where

$$
\begin{aligned}
\eta^{5} & =\frac{\theta}{\gamma} \sum_{i=1}^{2} \frac{\partial N^{i}}{\partial G}+\sum_{i=1}^{2}\left[\left[b+T^{i}\right]+\sum_{j=1}^{J} t_{j}\left[c_{j}^{i}-c_{j}^{u n}\right]\right] \frac{\partial N^{i}}{\partial G} \\
\Phi & =\sum_{i=1}^{2} \psi^{i} M R S_{G B}^{i}+\psi^{u n} M R S_{G B}^{u n}
\end{aligned}
$$


Proof. See the Appendix.

The formula for the public good deviates from the Samuelson condition by five additional terms. The second term on the right hand side depends on the difference between the marginal valuation of the public good by the mimicker and the marginal valuation of the public good by the low ability type. It reflects the self-selection constraint in the sense that the more (less) the mimicker values the public good, relative to the valuation of the public good by the low ability type, the stronger (weaker) will be the incentives for the government to discourage mimicking by reducing the public good. The third term originates from the influence of the public good on the commodity tax payment, which arises via changes in the compensated demand functions. These effects are discussed by Boadway and Keen (1993) and Edwards et al. (1994). With exogenous wage rates and no unemployment, the second and third terms on the right hand side of equation (44), together, determine whether the sum of marginal rates of substitution between the public good and private consumption should exceed, or fall short of, the marginal rate of transformation.

Under endogenous wage rates, the self-selection constraint will also influence the provision of the public good via the fourth term on the right hand side. If $\partial \phi / \partial G>0(<0)$, an increase in the public good makes mimicking less (more) attractive by increasing (decreasing) the wage ratio which, in turn, induces the government to provide more (less) of the public good than when the wage rates are exogenous. The fifth term on the right hand side reflects the employment effect associated with the public good, and the two components of $\eta^{5}$ are related to the employment restriction and the public budget constraint, respectively. By analogy to the employment effects discussed above in the context of other policy instruments, there is an incentive to provide more (less) of the public good if the public good increases 
(decreases) employment.

The final term on the right hand side of equation (44) suggests an interesting relationship between the consumption of private and public goods, which is due to the self-selection constraint and the influence of public policy on the employment. Consider first the relationship between the consumption of private and public goods among the unemployed, and notice that the government can secure the minimum utility level, $\bar{u}^{u n}$, of the unemployed by different combinations of $B^{u n}$ and $G$. By recalling that

$$
\psi^{u n}=\lambda \widehat{v}_{h}^{2}\left(\partial \phi / \partial B^{u n}\right) l^{1} / \gamma+\eta^{3},
$$

it becomes clear how the provision of the public good also depends on the 'self-selection' and employment effects associated with the choice of unemployment income. If $\partial \phi / \partial B^{u n}<0$ and $\eta^{3}<0$, both the self-selection constraint and the employment effect tend to reduce the optimal unemployment income. In this case, $\psi^{u n}<0$ and contributes to make $\Phi$ negative. As such, it will also contribute to increase the public good. The intuition is that the unemployment income is costly in the sense of making mimicking more attractive and/or reducing the employment. The government will then choose a lower level of unemployment income than otherwise and 'compensate' the unemployed by providing more of the public good. If, on the other hand, the term $\partial \phi / \partial B^{u n}>0$ and $\eta^{3}>0$, the argument goes the other way around. A similar interpretation can be given to the terms $\psi^{1} M R S_{G B}^{1}$ and $\psi^{2} M R S_{G B}^{2}$ in $\Phi$. For instance, if $\psi^{1}<0\left(\psi^{2}<0\right)$, private consumption is costly, in terms of self-selection and employment, which induces the government to choose a lower level of $B^{1}\left(B^{2}\right)$ than otherwise, and then compensate the employed low (high) ability type by providing more of the public good.

Let us return to the final term on the right hand side of equation (40). Consider first the part of $\Omega_{j}$ reflecting the consumption of commodity $j$ by the unemployed, $\psi^{u n} c_{j}^{u n}$. It is clear that the greater $\psi^{u n}$, ceteris paribus, 
the smaller will be the right hand side and, as a consequence, the greater the reduction in the compensated demand functions following an increase in the tax on commodity $j$. The interpretation is that if $\psi^{u n}$ is small, the government will have chosen a relatively low level of unemployment income, which makes the commodity taxes effective instruments for influencing the utility of private consumption. This suggests that if the self-selection constraint and/or concern for employment have forced the government to choose a low level of unemployment income, there will be an incentive to compensate the unemployed both via the public good and via lower commodity taxes. The reason for using both the public good and the commodity tax system in this way is, of course, that these two policy instruments are not perfect substitutes to one another. If $\psi^{\text {un }}$ is large, on the other hand, the unemployment income will be relatively large, and it is no longer necessary to stimulate the private consumption via lower commodity taxes. In other words, if higher commodity taxes do not prevent the government from reaching the minimum utility level of the unemployed, there is an incentive to choose higher commodity taxes than otherwise. We can interpret the terms $\psi^{1} c_{j}^{1}$ and $\psi^{2} c_{j}^{2}$ in a similar way: if $B^{1}$ and $B^{2}$ are relatively low (high), because of the self-selection constraint and/or employment effects, there is a tendency to choose lower (higher) commodity taxes than otherwise.

\section{Summary and Discussion}

This paper concerns optimal taxation and provision of a public good in the context of the mixed tax problem, where the government uses a nonlinear income tax and linear commodity taxes. In comparison with the previous studies on optimal taxation and provision of public goods within the mixed tax problem (or when the only tax instrument is a nonlinear income tax), which have been carried out under perfect competition, we assume that the 
economy is characterized by excess supply of labor as a result of the influence of unions over wage formation. The analysis is based on the familiar two type framework, in which self-selection plays a central role. Except for the description of the labor market, the model resembles that used by Edwards et al. (1994) in the sense of focusing the attention on the simultaneous choices of nonlinear income taxation, linear commodity taxation and the provision of a public good. However, since the equilibrium in our case is characterized by unemployment, the revenues are not only used for the purpose of providing a public good: the choice set of the government also includes an unemployment benefit.

In an economy which is characterized by unemployment, it becomes important to consider how the policy instruments influence the employment. Therefore, the policy rules familiar from previous studies are here augmented with so called employment effects, which are associated with the employment restriction and the public budget constraint. These employment effects suggest that, if a certain policy instrument tends to increase (decrease) the employment, there is an incentive for the government to use more (less) of that policy instrument than otherwise. In addition, the influence of the selfselection constraint is more complicated here than in most previous studies, since the wage rates are endogenous. If a change in one of the policy instruments affects the ratio between the wage rates of the two ability types, it also affects the labor input required by the high ability type to mimic the low ability type and, therefore, the incentives for mimicking.

The effective marginal tax rate of employed individuals of each ability type can be either positive or negative. This means a broader set of possible policies than under fixed wage rates and perfect competition. Furthermore, and in addition to the employment effects, the result also imply an interesting relationship between the consumption of private and public goods. If 
the employment restriction and/or the self-selection constraint have made the government choose the income taxes in such a way that the private consumption levels become relatively low, it will to some extent compensate the consumers by providing more of the public good and by choosing lower commodity taxes than otherwise.

\section{APPENDIX}

\section{Proof of Proposition 1}

By substituting equation (9) into equation (32), we obtain

$$
\tau_{y}^{i}=1+\frac{1}{w^{i}} \sum_{j=1}^{J} t_{j} \frac{\partial c_{j}^{i}}{\partial l^{i}}-\frac{1}{w^{i}} \frac{v_{h}^{i}}{v_{B}^{i}}\left[1-\sum_{j=1}^{J} t_{j} \frac{\partial c_{j}^{i}}{\partial B^{i}}\right]
$$

We can then rewrite equation (A1) by using equations (6) and (7)

$$
\tau_{y}^{i}=1-\frac{1}{w^{i}} \sum_{j=1}^{J} q_{j} \frac{\partial c_{j}^{i}}{\partial l^{i}}-\frac{1}{w^{i}} \frac{v_{h}^{i}}{v_{B}^{i}} \sum_{j=1}^{J} q_{j} \frac{\partial c_{j}^{i}}{\partial B^{i}}
$$

As a final step, let us multiply the quotient $v_{h}^{1} / v_{B}^{1}$ by the right hand side of equation (28), while observing that the resulting expression is equal to the right hand side of equation (27). By rearranging this expression, we have

$$
\left[\lambda \hat{v}_{B}^{2}-\lambda \hat{v}_{h}^{2} \frac{\partial \phi}{\partial B^{1}} l^{1}\right] \frac{v_{h}^{1}}{v_{B}^{1}}=\lambda \hat{v}_{h}^{2}\left[\phi+\frac{\partial \phi}{\partial l^{1}} l^{1}\right]+\gamma\left[\eta_{l}^{1}+\frac{v_{h}^{1}}{v_{B}^{1}} \eta_{B}^{1}\right]+\gamma \tilde{w}^{1} N^{1} \tau_{y}^{1}
$$

where we have used the definition of $\tau_{y}^{i}$ in equation (A2). By rearranging equation (A3), we obtain equation (33).

Proof of Proposition 4

By using equations (6), (28), (30), (37) and (39), we have 


$$
\begin{aligned}
0= & \lambda \hat{v}_{B}^{2}\left[\hat{c}_{j}^{2}-c_{j}^{1}\right]-\gamma\left[\sum_{i=1}^{2} N^{i} c_{j}^{i}+U c_{j}^{u n}\right] \\
& +\gamma\left[\sum_{i=1}^{2} N^{i} c_{j}^{i} \sum_{k=1}^{J} t_{k} \frac{\partial c_{k}^{i}}{\partial B^{i}}+U c_{j}^{u n} \sum_{k=1}^{J} t_{k} \frac{\partial c_{k}^{u n}}{\partial B^{u n}}\right] \\
& +\gamma \psi^{1} c_{j}^{1}+\gamma \psi^{2} c_{j}^{2}+\gamma \psi^{u n} c_{j}^{u n}+\lambda \hat{v}_{h}^{2} l^{1} \frac{\partial \phi}{\partial p_{j}} \\
& -\gamma\left[\sum_{i=1}^{2} N^{i} \sum_{k=1}^{J} q_{k} \frac{\partial c_{k}^{i}}{\partial p_{j}}+U \sum_{k=1}^{J} q_{k} \frac{\partial c_{k}^{u n}}{\partial p_{j}}\right]+\gamma \eta^{4}
\end{aligned}
$$

Note that $\sum_{k=1}^{J} p_{k} c_{k}^{i}=B^{i}$ implies

$$
\sum_{k=1}^{J} q_{k} \frac{\partial c_{k}^{i}}{\partial p_{j}}=-c_{j}^{i}-\sum_{k} t_{k} \frac{\partial c_{k}^{i}}{\partial p_{j}}
$$

The Slutsky equation and the symmetry of the Slutsky matrix imply

$$
\begin{aligned}
\frac{\partial \bar{c}_{k}^{i}}{\partial p_{j}} & =\frac{\partial c_{k}^{i}}{\partial p_{j}}+\frac{\partial c_{k}^{i}}{\partial B^{i}} c_{j}^{i} \\
\frac{\partial \bar{c}_{k}^{i}}{\partial p_{j}} & =\frac{\partial \bar{c}_{j}^{i}}{\partial p_{k}}
\end{aligned}
$$

By substituting equations (A5) and (A6) into equation (A4), we obtain equation (40).

\section{Proof of Proposition 5}

By using equations (1), (8) and (10), the first order condition for the public good can be written as

$$
\begin{gathered}
v_{G}^{1}+[\mu+\lambda] v_{G}^{2}+\beta v_{G}^{u n}-\lambda \hat{v}_{G}^{2}+\lambda \hat{v}_{h}^{2} l^{1} \frac{\partial \phi}{\partial G}+\gamma \eta^{5} \\
+\quad \gamma\left[-\sum_{i=1}^{2} N^{i} \sum_{j=1}^{J} q_{j} \frac{\partial c_{j}^{i}}{\partial G}-U \sum_{j=1}^{J} q_{j} \frac{\partial c_{j}^{i}}{\partial G}-r\right]=0
\end{gathered}
$$

We shall begin by using the identities

$$
v^{i}\left(B^{i}\left(G, l^{i}, \bar{u}^{i}, \mathbf{p}\right), G, l^{i}, \mathbf{p}\right) \equiv \bar{u}^{i}
$$




$$
v^{u n}\left(B^{u n}\left(G, \bar{u}^{u n}, \mathbf{p}\right), G, \mathbf{p}\right) \equiv \bar{u}^{u n}
$$

and noticing that the derivatives with respect to $G$ can be written as

$$
\frac{\partial B^{i}}{\partial G}=-M R S_{G B}^{i} \quad \frac{\partial B^{u n}}{\partial G}=-M R S_{G B}^{u n}
$$

We will also make use of the identities

$$
\begin{gathered}
c_{j}^{i}\left(B^{i}\left(G, l^{i}, \bar{u}^{i}, \mathbf{p}\right), G, l^{i}, \mathbf{p}\right) \equiv \bar{c}_{j}^{i}\left(G, l^{i}, \bar{u}^{i}, \mathbf{p}\right) \\
c_{j}^{u n}\left(B^{u n}\left(G, \bar{u}^{u n}, \mathbf{p}\right), G, \mathbf{p}\right) \equiv \bar{c}_{j}^{u n}\left(G, \bar{u}^{u n}, \mathbf{p}\right)
\end{gathered}
$$

By differentiating equations (A11) and (A12) with respect to $G$ and using (A10), we have

$$
\begin{aligned}
\frac{\partial c_{j}^{i}}{\partial G} & =\frac{\partial \bar{c}_{j}^{i}}{\partial G}+M R S_{G B}^{i} \frac{\partial c_{j}^{i}}{\partial B^{i}} \\
\frac{\partial c_{j}^{u n}}{\partial G} & =\frac{\partial \bar{c}_{j}^{u n}}{\partial G}+M R S_{G B}^{u n} \frac{\partial c_{j}^{u n}}{\partial B^{u n}}
\end{aligned}
$$

The next step is to multiply equations (A13) and (A14) by $q_{j}$, sum over $j$ and substitute into equation (A7). In addition, we use equations (28), (30) and (37) to substitute for $v_{B}^{1},[\mu+\lambda] v_{B}^{2}$ and $v_{B}^{u n}$, respectively, in equation (A7).

Finally, let us define the identities

$$
\begin{aligned}
& \sum_{j=1}^{J} p_{j} \bar{c}_{j}^{i}\left(G, l^{i}, \bar{u}^{i}, \mathbf{p}\right)=B^{i}\left(G, l^{i}, \bar{u}^{i}, \mathbf{p}\right) \\
& \sum_{j=1}^{J} p_{j} \bar{c}_{j}^{u n}\left(G, \bar{u}^{u n}, \mathbf{p}\right)=B^{u n}\left(G, \bar{u}^{u n}, \mathbf{p}\right)
\end{aligned}
$$

By differentiating equations (A15) and (A16) with respect to $G$ and using (A10), we have

$$
\begin{gathered}
\sum_{j=1}^{J} q_{j} \frac{\partial \bar{c}_{j}^{i}}{\partial G}=-M R S_{G B}^{i}-\sum_{j=1}^{J} t_{j} \frac{\partial \bar{c}_{j}^{i}}{\partial G} \\
\sum_{j=1}^{J} q_{j} \frac{\partial \bar{c}_{j}^{u n}}{\partial G}=-M R S_{G B}^{u n}-\sum_{j=1}^{J} t_{j} \frac{\partial \bar{c}_{j}^{u n}}{\partial G}
\end{gathered}
$$

We can then derive equation (44). 


\section{References}

[1]Andersen, T.M., Sandemann Rasmussen, B. and Rose Sörensen, J. (1996) Optimal Fiscal Policy in Open Economies with Labor Market Distortions. Journal of Public Economics 63, 103-117.

[2]Aronsson, T. and Sjögren, T. (2001) Optimal Taxation and Provision of Public Goods in a Unionized Economy. Department of Economics, University of Ume.

[3]Atkinson, A., B. (1977), "Optimal taxation and the direct versus indirect tax controversy", Canadian Journal of Economics 10, 590-606.

[4]Atkinson, A., B. and Stiglitz, J., E. (1976), "The design of tax structure: direct versus indirect taxation", Journal of Public Economics 1, 55-75.

[5]Boadway, R. and Keen, M., J. (1993), "Public goods, self-selection and optimal income taxation", International Economic Review 34, 463-478.

[6]Boeters, S. and Schneider, K. (1999) Government versus Union: The Structure of Optimal Taxation in a Unionized Labor Market. Finanzarchiv 56, 174-187.

[7]Bovenberg, A.L. and van der Ploeg, F. (1996) Optimal Taxation, Public Goods and Environmental Policy with Involuntary Unemployment. Journal of Public Economics 62, 69-83.

[8]Christiansen, V. (1981), "Evaluation of projects under optimal taxation", Review of Economic Studies 48, 447-457.

[9]Christiansen, V. (1984) Which Commodity Taxes should Supplement the Income Tax? Journal of Public Economics 24, 195-220. 
[10]Edwards, J., Keen, M. and Tuomala, M. (1994), "Income tax, commodity taxes and public good provision", Finanzarchiv 51, 472-497.

[11]Koskela, E. and Schöb, R. (2000) Optimal Factor Income Taxation in the Presence of Unemployment. Center for Economic Studies. Working paper no 279 .

[12]Mirrlees, J., A. (1976), "Optimal tax theory: a synthesis", Journal of Public Economics 6, 327-358.

[13] Oswald, A.J. (1985) The Economic Theory of Trade Unions: An Introductory Survey. The Scandinavian Journal of Economics 87, 160-193.

[14]Stern, N., H. (1982), "Optimum taxation with errors in administration", Journal of Public Economics 17, 181-211.

[15]Stiglitz, J., E. (1982), "Self-selection and Pareto efficient taxation", Journal of Public Economics 17, 213-240.

[16]Tuomala, M. (1990), "Optimal income taxation and redistribution", Oxford. 